\title{
Endoscopic Retroperitoneal Necrosectomy for Infected Pancreatic Necrosis Using a Self-Expandable Metal Stent
}

\author{
Gaurav Patil Amit Maydeo Ankit Dalal Arun lyer Rajdeep More \\ Shivaji Thakare
}

Baldota Institute of Digestive Sciences, Gleneagles Global Hospital, Mumbai, India

\section{Keywords}

Walled-off pancreatic necrosis · Retroperitoneal necrosectomy $\cdot$ Self-expandable $\cdot$ Metallic stent

\section{Abstract}

Infected walled-off pancreatic necrosis (WOPN) is a severe complication of acute pancreatitis. Surgery in these critically ill patients can be associated with increased morbidity and mortality. Hence, minimally invasive therapies have emerged as an alternative to surgery. Herein, we report a case of severe acute pancreatitis with WOPN which was treated percutaneously with a flexible endoscope through an esophageal self-expanding metal stent using a total retroperitoneal approach. Percutaneous direct endoscopic necrosectomy ( $p$ DEN) using the retroperitoneal route improved the patient's parameters dramatically with resolution of sepsis without the need for surgery. $p$-DEN using a flexible endoscope passed through a large bore metal stent shows promise in selected patients with WOPN and can be used in patients who are not ideal candidates for transmural or surgical drainage.

๑) 2021 Sociedade Portuguesa de Gastrenterologia Published by S. Karger AG, Basel

\begin{abstract}
Necrosectomia retroperitoneal endoscópica para uma necrose pancreática infectada com a utilização de uma prótese metálica auto-expansível
\end{abstract}

Palavras Chave

Necrosectomia retroperitoneal · Prótese metálica autoexpansível · Necrose pancreática walled-off

\section{Resumo}

A necrose pancreática infectada walled-off (WOPN) é uma complicação grave da pancreatite aguda (PA). A cirurgia nestes doentes críticos pode associar-se a um aumento da morbimortalidade. Assim, técnicas minimamente invasivas surgiram como alternativa à cirurgia. Reportamos um caso de PA grave com WOPN que foi tratada de forma percutânea com um endoscópio flexível através de uma prótese metálica auto-expansível usando uma abordagem totalmente retroperitoneal. A necrosectomia retroperitoneal endoscópica direta ( $p-D E N)$ usando a via retroperitoneal melhorou os parâmetros do doente significativamente com resolução da sépsis sem necessidade de cirurgia. p-DEN usando um endoscópico flexível que passa através uma prótese metálica de grande diâmetro pa-

$\begin{array}{ll}\text { karger@karger.com } & \text { (c) 2021 Sociedade Portuguesa de Gastrenterologia } \\ \text { www.karger.com/pjg } & \text { Published by S. Karger AG, Basel } \\ \text { Karger } & \text { This article is licensed under the Creative Commons Attribution- } \\ \text { NonCommercial-NoDerivatives 4.0 International License (CC BY- } \\ \text { NC-ND) (http://www.karger.com/Services/OpenAccessLicense). } \\ \text { Usage and distribution for commercial purposes as well as any dis- } \\ \text { tribution of modified material requires written permission. }\end{array}$

karger@karger.com 
rece ser uma técnica promissora em alguns doentes com WOPN, podendo ser utilizada em doentes que não são candidatos ideais para uma drenagem transmural ou cirúrgica.

(C) 2021 Sociedade Portuguesa de Gastrenterologia Publicado por S. Karger AG, Basel

\section{Introduction}

Clinical management of infected walled-off pancreatic necrosis (WOPN) has always been challenging. Currently, the standard treatment for WOPN is a step-up approach or surgical intervention with necrosectomy and drainage [1]. Conventional surgery is generally the only possible treatment option at most centers despite its high complication rates. Minimally invasive approaches such as minimally invasive retroperitoneal surgical necrosectomy, percutaneous catheter drainage, and endoscopic transluminal drainage are thought to induce less physiological stress owing to minimal activation of the inflammatory processes compared with conventional surgery [2-4]. Endoscopic drainage requires suitable anatomy for the collection to be accessible from a stable location in the gastrointestinal tract for adequate drainage. Occasionally, the collection can extend either caudally along the paracolic gutters or cranially to the lesser sac. WOPN extending into these locations is always challenging to manage, especially if a patient has multiple, non-communicating collections [5]. In this case report, we describe a novel approach for the treatment of a similar WOPN with ill-defined walls via percutaneous direct endoscopic necrosectomy ( $\mathrm{p}-\mathrm{DEN}$ ) using an esophageal self-expanding metal stent (SEMS).

\section{Case Report}

A 59-year-old female with hypertension and hypothyroidism on medications was recently diagnosed with severe acute necrotizing pancreatitis with an acute necrotic collection (Fig. 1a) which was managed conservatively in September 2018. A month later, the patient presented with fever, abdominal pain, and hypotension. On examination, the patient had diffuse tenderness over the abdomen. The patient was resuscitated with parenteral fluid therapy, non-invasive ventilation, and vasopressors. Empirical parenteral antibiotics (cefoperazone 1,000 mg + sulbactam $500 \mathrm{mg}$ IV Q12H) were started after collecting blood cultures. Laboratory tests demonstrated hemoglobin of $8.6 \mathrm{gm} / \mathrm{dL}$, leukocytosis with a left shift, high C-reactive protein of $120 \mathrm{mg} / \mathrm{L}$, and $\mathrm{PaO}_{2} / \mathrm{FiO}_{2}$ ratio of 234 . Liver and renal function tests were within the normal limits. The patient underwent a computed tomography (CT) scan of the abdomen which showed a large ill-defined necrotizing peripancreatic fluid collection containing air foci. This collection replaced the neck, body, and tail, extending superiorly to gastrosplenic fat and bilaterally along the paracolic gutters. There was no evidence of any bowel leak (Fig. 1b, c).

Despite being on antibiotics, the patient did not improve clinically even after $24 \mathrm{~h}$ and was planned for a CT-guided percutaneous drainage. Following a step-up approach, a 12-Fr percutaneous pigtail catheter was inserted into the WOPN from the left subcostal site, and fluid aspirate was sent for culture which grew multidrug-resistant Klebsiella pneumoniae. Antibiotics were tailored as per the culture sensitivity pattern (meropenem $1 \mathrm{~g}$ IV loading dose, maintenance $1 \mathrm{~g} / \mathrm{Q} 8 \mathrm{H}$ and colistin 9-MIU IV loading dose, maintenance 4.5-MIU/Q12H) and continued up to 18 days (Fig. 1d). However, the patient condition continued to worsen despite upgrading the size of the pigtail catheter to $26 \mathrm{Fr}$ (anticipating better drainage). Therefore, it was decided to use a percutaneous access to enter the WOPN for thorough debridement and washout using flexible endoscopy by placing a wide bore fully covered esophageal SEMS.

Under propofol-based total intravenous anesthesia (TIVA), we replaced the pigtail catheter by an esophageal SEMS using the Seldinger technique. The WOPN was visualized by contrast injection through the pigtail catheter under fluoroscopy. A 0.035-inch guidewire (Dreamwire, Boston Scientific, USA) was introduced through the pigtail catheter, and the latter was removed, with the wire was left in place. Subsequently, a 20-mm dilation balloon (CRE Wireguided, Boston Scientific) was used to dilate the tract over the guidewire under fluoroscopic guidance to facilitate SEMS placement. A WallFlex fully covered esophageal stent (Boston Scientific) with a diameter of $20 \mathrm{~mm}$ and a length of $100 \mathrm{~mm}$ was inserted over the guidewire into the cavity. A flexible gastroscope (GIF-1TQ190, Olympus, Japan) was introduced through the SEMS and DEN was performed through the stent by irrigation with sterile saline, diluted betadine and hydrogen peroxide, and a combination of stone retrieval basket and polypectomy snares. To provide continuous drainage, we inserted a 7-Fr pigtail stent (plastic biliary stent, Boston Scientific) through the SEMS. The SEMS and the plastic stent were secured by suturing them to the skin (Fig. 1e).

We repeated the necrosectomy procedure (in total 4 sessions over a period of 2 weeks, under TIVA) until collection resolution (Fig. 1f). We covered the tract with a colostomy bag and changed it as per requirement. The deployment of percutaneous SEMS and p-DEN are depicted in Figure $2 a-f$. The patient showed considerable clinical improvement and was discharged 3 days after the last necrosectomy session. The patient was followed up in the outpatient clinic after 2 weeks. The drainage output progressively declined and after 4 weeks of SEMS placement it was removed and the track closed by secondary intention within 3 months.

\section{Discussion}

By using an esophageal SEMS and performing a percutaneous retroperitoneal approach, we successfully performed p-DEN of the abovementioned ill-defined WOPN. This is the first of such cases in an Indian context whereby an esophageal SEMS is used for p-DEN. Currently, many endoscopic drainage options exist to improve the step-up approach for WOPN in order to avoid 

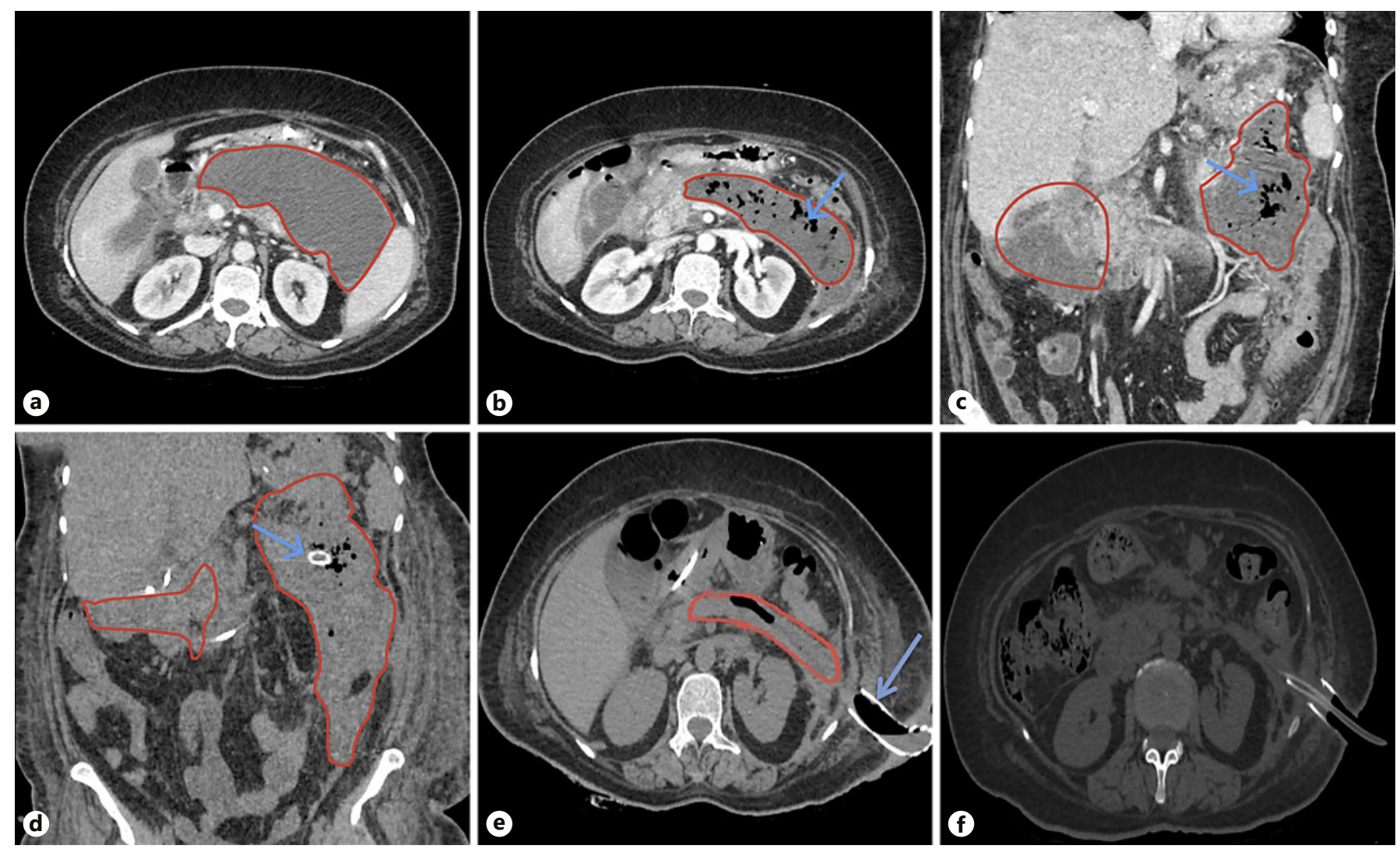

Fig. 1. a Baseline CT abdomen depicting severe acute necrotizing pancreatitis with an acute necrotic collection. b, c CT abdomen after 4 weeks showing a large necrotizing peripancreatic fluid collection containing air foci (arrow), replacing the neck, body, and tail of the pancreas (measuring $14 \times 4 \mathrm{~cm}$ in the transverse axis). There is continuity to the retrogastric region extending superiorly to gastrosplenic fat, to the right side along the hepatic flexure of the colon and in the subhepatic-pericholecystic region (measuring 8.6

surgical necrosectomy [6]. A literature search resulted in 9 studies describing p-DEN using a percutaneous SEMS in the treatment of necrotizing pancreatitis. This included 2 case series and 7 case descriptions [7-15]. Thorsen et al. [13] reported 5 cases with a technical success of $100 \%$, while the clinical success was $80 \%$ after an average of 5.75 necrosectomy sessions. Tringali et al. [14] reported 3 cases of WOPN resolution by percutaneous necrosectomy through SEMS after an average of 3 endoscopic sessions. No procedure-related adverse events were seen. Saumoy et al. [15] reported 9 patients with WOPN who underwent p-DEN which was combined with endoscopic transmural drainage and necrosectomy (ETDN) with $100 \%$ technical success and $89 \%$ clinical success rates.

This patient had a large collection (WOPN) with paracolic extension which was not accessible endoscopically.

Endoscopic Necrosectomy for Infected Pancreatic Necrosis $\times 7.8 \times 4.8 \mathrm{~cm}$ ), to the left side along the left anterior pararenal fascia medial to the left colon, and extending posteriorly in close association with the left psoas muscle (measuring $5.2 \times 5.3 \times 2.3$ $\mathrm{cm}$ ). d CT-guided percutaneous drainage using a 12-Fr percutaneous pigtail catheter seen in situ (arrow). e CT showing a percutaneously placed SEMS for performing $\mathrm{p}$-DEN via a retroperitoneal route. $\mathbf{f} \mathrm{CT}$ after 4 sessions of $\mathrm{p}$-DEN showing resolution of the WOPN.

The abdominal CT scan suggested that it could be approached through a retroperitoneal route. Thereafter, an initial step-up approach with plastic stents was not clinically effective. Hence, a decision was taken to drain the WOPN using a minimally invasive approach (P-DEN) as the patient was not fit for major surgery. We accessed the WOPN via a retroperitoneal approach rather than a transperitoneal approach as the former has fewer complications [16]. Also, we relied solely on p-DEN rather than a combination of p-DEN and ETDN owing to the ill-defined walls in our case. The WOPN walls were not mature even after 4 weeks and we were compelled to make an early decision for p-DEN. Corroborating our approach, a recent study showed better outcomes with less organ failure and in-hospital mortality when percutaneous drainage is performed early in the course of necrotizing pancreatitis [17]. There 

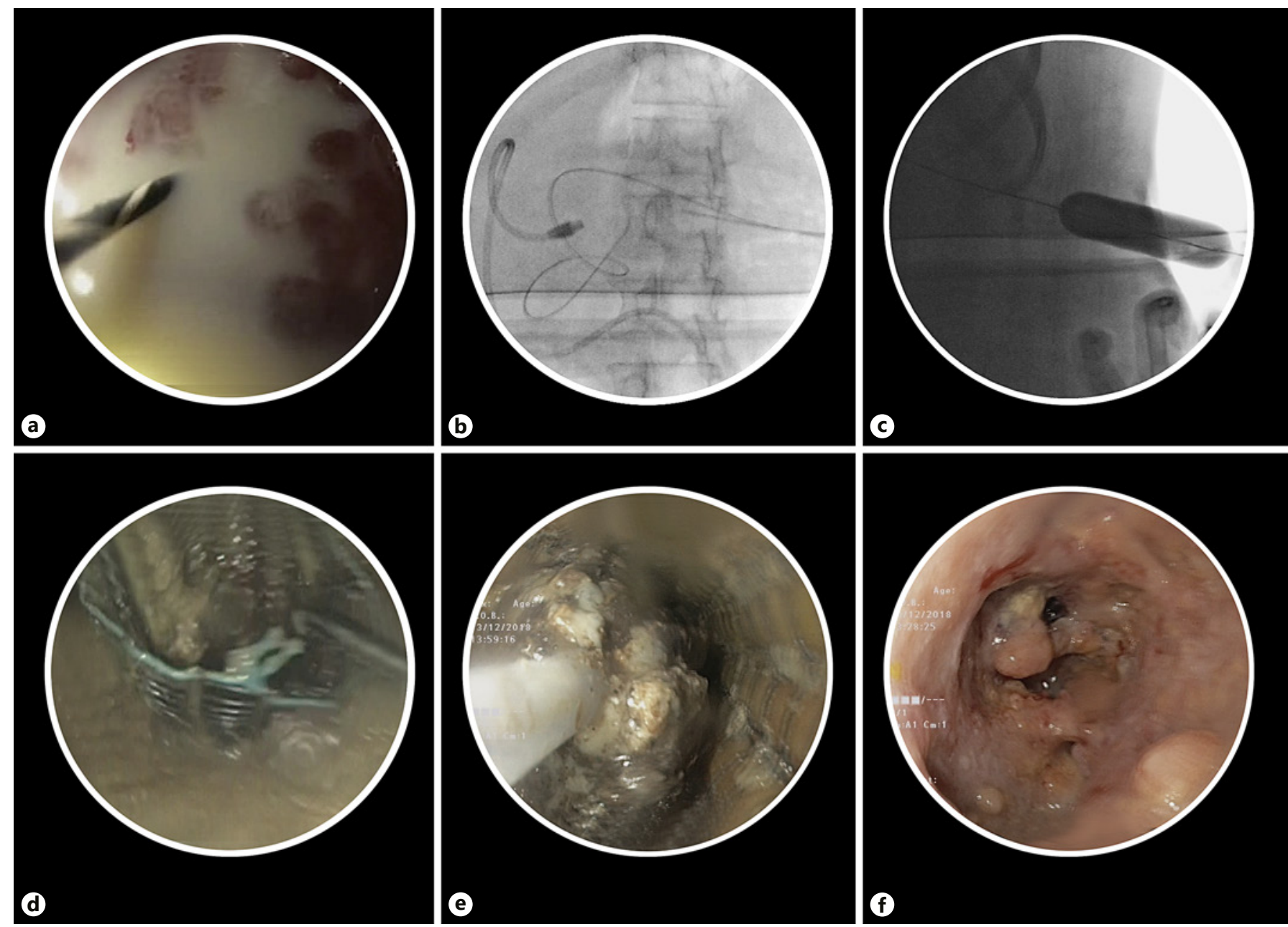

Fig. 2. Technique of percutaneous SEMS placement. a Removal of the small caliber plastic pigtail catheter (on the left side) over the guidewire. b Fluoroscopic image showing the guidewire and the right sided pigtail catheter. $\mathbf{c}$ Wire guided CRE balloon dilatation

to facilitate SEMS placement. d Esophageal SEMS deployed percutaneously along the dilated tract for p-DEN. e Necrotic material being removed using a stone retrieval basket. $\mathbf{f}$ Endoscopic view of the WOPN cleared of infected debris following p-DEN.

have been reports of drainage through single or multiport percutaneous routes and through sinus tract endoscopy $[17,18]$. However, we felt that using a SEMS might help in increasing the technical success. Larger collections can also be drained with minimal invasive techniques. MRI is preferred over CT to assess drainage because it is better at detecting non-liquefied material [19].

An RCT [1] showed the superiority of a step-up approach using video-assisted retroperitoneal debridement (VARD) over open surgery, whereas another RCT showed a superiority of ETDN over surgery [4]. A recent RCT showed the advantages of an endoscopic step-up approach compared to a step-up approach of percutaneous catheter drainage and VARD [20]. EUS-guided transmural drain-

age has also shown similar technical and clinical success compared to percutaneous approaches [21]. Owing to multiple results seen from these trials, there is a need for randomized studies with large sample sizes followed by appropriate systematic reviews. The ideal drainage for this collection would have been a dual approach of EUS cystogastrostomy and a percutaneous technique. Since this was a very large collection with paracolic extension, we decided to initially proceed with the percutaneous approach [22] followed by EUS drainage if needed. We placed a SEMS and through the SEMS we could perform DEN. We achieved a good necrosectomy response over a few sessions using this approach as the symptoms gradually reduced and the size of collection decreased. In view of im- 
proving clinical and laboratory parameters, we continued to perform DEN through this route and achieved a near complete necrosectomy response, thereby avoiding an additional EUS drainage and its added costs.

Navarrete et al. [3] proposed percutaneous access via a large-bore esophageal SEMS with the aim of making access to the necrotic cavity easier and faster. The primary indication for $\mathrm{p}-\mathrm{DEN}$ is the presence of infected necrosis. If the WOPN becomes obstructed or fistulized to adjacent anatomical structures, compressing into the surrounding vasculature, the patient needs rapid intervention. This technique has numerous advantages. It allows for a wide opening access and better stability of the scope (as compared to enteral and colonic stents) for endoscopic intervention with standard or even therapeutic endoscopes. A benefit of using SEMS in place of a large bore catheter is to sustain the patency of the tract and does not require re-dilatation during subsequent sessions, thereby allowing a permanent wide duct for drainage. Furthermore, it provides a larger drainage lumen which prevents obstruction from thick, tenacious necrotic material, which is common with WOPN. It allows easier observation of the drainage site and output between necrosectomy sessions. The collections can be drained on the most declivous side which guarantees better emptying in comparison to a transgastric approach, even when it would be feasible. Finally, p-DEN through SEMS can be performed with standard or therapeutic endoscopes under TIVA without the need for general anesthesia, which is often required for prolonged per-oral endoscopies. Due to its promising results as seen from multiple cases, $\mathrm{p}$-DEN can be used in the step-up approach for the management of WOPN. Disadvantages include more pain, stent dislocation, and fistula formation. Also, the question of possible infection access through a large bore stent is a matter of concern. Repeated procedures are often needed and may not be useful in the case of extensive necrosectomy [13]. This procedure can only be performed by experienced inter- ventional endoscopists with optimal radiological and surgical facilities in a tertiary care center [14].

To summarize, wide retroperitoneal access to WOPNs with SEMS followed by endoscopic necrosectomy is a safe and effective intervention in appropriately selected patients. These results need to be reproduced with a large patient cohort before this becomes the standard of care in this patient population.

\section{Acknowledgements}

We thank Mr. Sehajad Vora for acting as a chief technician and assisting during the procedure. We thank Dr. Nagesh Kamat for his assistance with manuscript preparation.

\section{Statement of Ethics}

This is a case report, hence ethical approval was not sought. We state that the subject gave written informed consent for the publication of her case.

\section{Conflict of Interest Statement}

There are no conflicts of interest to declare.

\section{Funding Sources}

The authors received no grants or financial support.

\section{Author Contributions}

A.M. oversaw the case. A.M., A.D., G.P., R.M. and A.I. were involved in the routine management of this case. G.P., A.D., S.T. and A.I. wrote the article. A.M. performed critical review of the article. All authors read and approved the final draft of the manuscript.

\section{References}

1 van Santvoort HC, Besselink MG, Bakker OJ, Hofker HS, Boermeester MA, Dejong CH, et al.; Dutch Pancreatitis Study Group. A stepup approach or open necrosectomy for necrotizing pancreatitis. N Engl J Med. 2010 Apr; 362(16): 1491-502.

2 Mui LM, Wong SK, Ng EK, Chan AC, Chung SC. Combined sinus tract endoscopy and endoscopic retrograde cholangiopancreatography in management of pancreatic necrosis and abscess. Surg Endosc. 2005 Mar;19(3):393-7.
3 Navarrete C, Castillo C, Caracci M, Vargas P, Gobelet J, Robles I. Wide percutaneous access to pancreatic necrosis with self-expandable stent: new application (with video). Gastrointest Endosc. 2011 Mar;73(3):609-10.

4 Bakker OJ, van Santvoort HC, van Brunschot S, Geskus RB, Besselink MG, Bollen TL, et al.; Dutch Pancreatitis Study Group. Endoscopic transgastric vs surgical necrosectomy for infected necrotizing pancreatitis: a randomized trial. JAMA. 2012 Mar;307(10):1053-61.
5 Teoh AY, Dhir V, Jin ZD, Kida M, Seo DW, Ho KY. Systematic review comparing endoscopic, percutaneous and surgical pancreatic pseudocyst drainage. World J Gastrointest Endosc. 2016 Mar;8(6):310-8.

6 Trikudanathan G, Attam R, Arain MA, Mallery S, Freeman ML. Endoscopic interventions for necrotizing pancreatitis. Am J Gastroenterol. 2014 Jul;109(7):969-81. 
7 D'Souza LS, Korman A, Carr-Locke DL, Benias PC. Percutaneous endoscopic necrosectomy. Endoscopy. 2017 Oct;49(10):E2423.

8 Sato S, Takahashi H, Sato M, Yokoyama M, Itoi T, Kawano Y, et al. A case of walled-off necrosis with systemic lupus erythematosus: successful treatment with endoscopic necrosectomy. Semin Arthritis Rheum. 2016 Oct; 46(2):e13-4.

9 Cerecedo-Rodriguez J, Hernández-Trejo A, Alanís-Monroy E, Barba-Mendoza JA, Benítez Tress-Faez MP, Figueroa-Barojas P. Endoscopic percutaneous pancreatic necrosectomy. Gastrointest Endosc. 2014 Jul;80(1): 165-6.

10 Kedia P, Parra V, Zerbo S, Sharaiha RZ, Kahaleh $\mathrm{M}$. Cleaning the paracolic gutter: transcutaneous endoscopic necrosectomy through a fully covered metal esophageal stent. Gastrointest Endosc. 2015 May;81(5): 1252.

11 Bakken JC, Baron TH. Use of partially covered and fully covered self-expandable metal stents to establish percutaneous access for endoscopic necrosectomy. Endoscopy. 2011; 43:A69.

12 Bakken JC, Baron TH. Pancreatic necrosectomy via percutaneous self-expandable metal stent placement. Gastrointest Endosc. 2011; 73(4):AB103.
13 Thorsen A, Borch AM, Novovic S, Schmidt PN, Gluud LL. Endoscopic Necrosectomy Through Percutaneous Self-Expanding Metal Stents May Be a Promising Additive in Treatment of Necrotizing Pancreatitis. Dig Dis Sci. 2018 Sep;63(9):2456-65.

14 Tringali A, Vadalà di Prampero SF, Bove V, Perri V, La Greca A, Pepe G, et al. Endoscopic necrosectomy of walled-off pancreatic necrosis by large-bore percutaneus metal stent: a new opportunity? Endosc Int Open. 2018 Mar;6(3):E274-8.

15 Saumoy M, Kumta NA, Tyberg A, Brown E, Lieberman MD, Eachempati SR, et al. Transcutaneous endoscopic necrosectomy for walled-off pancreatic necrosis in the paracolic gutter. J Clin Gastroenterol. 2018 May/Jun; 52(5):458-63.

16 Boumitri C, Brown E, Kahaleh M. Necrotizing Pancreatitis: Current Management and Therapies. Clin Endosc. 2017 Jul;50(4):357-65.

17 Sugimoto M, Sonntag DP, Flint GS, Boyce CJ, Kirkham JC, Harris TJ, et al. Better outcomes if percutaneous drainage is used early and proactively in the course of necrotizing pancreatitis. J Vasc Interv Radiol. 2016 Mar; 27(3):418-25.

18 Dhingra R, Srivastava S, Behra S, Vadiraj PK, Venuthurimilli A, Shalimar, et al. Single or multiport percutaneous endoscopic necrosectomy performed with the patient under conscious sedation is a safe and effective treatment for infected pancreatic necrosis (with video). Gastrointest Endosc. 2015 Feb;81(2): 351-9.

19 Kamal A, Singh VK, Akshintala VS, Kawamoto $\mathrm{S}$, Tsai S, Haider M, et al. CT and MRI assessment of symptomatic organized pancreatic fluid collections and pancreatic duct disruption: an interreader variability study using the revised Atlanta classification 2012. Abdom Imaging. 2015 Aug;40(6):1608-16.

20 van Brunschot S, van Grinsven J, van Santvoort HC, Bakker OJ, Besselink MG, Boermeester MA, et al.; Dutch Pancreatitis Study Group. Endoscopic or surgical step-up approach for infected necrotising pancreatitis: a multicentre randomised trial. Lancet. 2018 Jan;391(10115):51-8.

21 Arvanitakis M, Dumonceau JM, Albert J, Badaoui A, Bali MA, Barthet M, et al. Endoscopic management of acute necrotizing pancreatitis: european Society of Gastrointestinal Endoscopy (ESGE) evidence-based multidisciplinary guidelines. Endoscopy. 2018 May; 50(5):524-46.

22 Gluck M, Ross A, Irani S, Lin O, Hauptmann E, Siegal J, et al. Endoscopic and percutaneous drainage of symptomatic walled-off pancreatic necrosis reduces hospital stay and radiographic resources. Clin Gastroenterol Hepatol. 2010 Dec;8(12):1083-8. 